БЕЛИК Елена Александровна - аспирант кафедры социологических наук Социальнопсихологического института Кемеровского государственного университета (650000, Россия, г. Кемерово, ул. Красная, 6; eabelik@mail.ru)

ГОЛОВАЦКИЙ Евгений Васильевич - кандидат социологических наук, доцент; доцент кафедры социологических наук Социально-психологического института Кемеровского государственного университета (650000, Россия, г. Кемерово, ул. Красная, 6; хотаik@rambler.ru)

\title{
ТРАНСФОРМАЦИЯ ПОНЯТИЯ «ТЕРРОРИЗМ» В СОЦИАЛЬНО-ПОЛИТИЧЕСКИХ ПРАКТИКАХ СОВРЕМЕННОЙ РОССИЙСКОЙ ПОВСЕДНЕВНОСТИ
}

\begin{abstract}
Аннотация. Смысловая наполненность понятий, используемых в области социально-политических отношений, в последнее время претерпевает существенную трансформацию как в основном своем значении, так и в плане резонанса гражданского восприятия. Это обусловлено изменением в XX-XXI вв. объемов, качества и правил передачи информации, прежде всего в результате появления сети Интернет, посредством которой расширен круг информационных производителей и потребителей. При этом риски и угрозы, возникающие в процессе производства-передачи качества обозначения информации о чемлибо, могут носить скрытый характер и повлечь за собой непреднамеренные последствия, в т.ч. искажение узнавания/определения смыслов и значений. Такие риски могут обеспечиваться как социальным феноменом «эпохи постправды» - фейк ньюс, так и нарушением, в т.ч. неосознанным, порядка создания актов различения, именования, квалификации в целях последующего коммуникативного повествования. Авторы предлагают результаты анализа публикаций средств массовой информации, связанных с практиками повседневного информирования об одной из глобальных угроз постсовременного мира - терроризме. Рамки понятия ограничены индикаторами соседства, представляющими систему локальных связей в контексте социологии повседневности. В результате установлено, что смысловое значение заголовков публикаций “соседи-террористы», “соседский террор» определенно различаются в содержании внутреннего смыслового наполнения. Полученные данные «вольного» обозначения понятия позволили сделать вывод, что терроризм включился в повседневные практики людей, и это несет в себе риски деформации системы социальных кодов и значений.
\end{abstract}

Ключевые слова: повседневное взаимодействие, социологические исследования, терроризм, интерпретации, социально-политическое взаимодействие

$\mathrm{B}$ заимная ежедневная координированная деятельность людей, возникающая в процессе совместных практик, привычные, обыденные ситуации в своей совокупности образуют повседневность социальной жизни. А. Шюц определяет повседневный мир как мир рутинной деятельности, мир работы [Шюц 2004: 406]. Формируемые в результате постоянных интеракций практики повседневной деятельности в будущем снова применяются и в результате постоянного повторения закрепляются в сознании, создавая устойчивые структуры (фреймы). В качестве реальности, интерпретируемой людьми и имеющей субъективную значимость, повседневная жизнь предполагает постоянный анализ социально-коммуникативных взаимодействий и культурной организации общества, который в исследовательском плане может производиться посредством фрейм-анализа как инструмента аналитического наблюдения повседневной событийности, ориентированного на изучение контекстов элементарных событий [Вахштайн 2007: 10].

Трансформация наполнения информацией коммуникативного пространства, связанного с лавинообразным нарастанием ее объема в XX в., привела 
к возникновению такого социально-экономического и информационно-коммуникативного феномена, как big-data, классическими источниками которого считаются ресурсы Интернета и социальные медиа. «Доставка» информации в современных условиях социальной коммуникации обеспечивается ее аккумулированием и массированной публичной передачей, в т.ч.средствами массовой информации (СМИ).

Политический дискурс оказывается интегрированным в массмедиа посредством институциональных, функциональных и инструментальных скреп, которые участвуют в формировании социально-политического пространства, и влияет на восприятие и осмысление мира современными гражданами/ пользователями в повседневной жизни. В результате СМИ в настоящее время выполняют не столько информационную, сколько идеологическую роль, т.е. не столько транслируют информацию, отражая объективное состояние общественных настроений, сколько выступают инструментом, который эти настроения формирует, направляет с помощью определенным образом преподносимой информации [Харламова 2012: 41]. Поэтому мы полагаем, что методология фреймирования может применяться в целях анализа СМИ как инструмента отражения повседневной жизни людей.

Транслируемая СМИ картина мира представляет собой не имеющее физических границ концептуально бесконечное сообщение, своеобразный метадискурс, порождаемый объективной социальной реальностью и адресованный субъектам этой реальности [Комаров 2014: 124]. При этом многоканальность передачи информации, как правило, представляет определенный набор механизмов, способов организации информационного материала, которые производители медиасообщений используют при их конструировании, воздействуя на процессы формирования социальной структуры как существенного элемента реальности повседневной жизни.

С развитием коммуникативного онлайн-пространства граница между официальными новостями, создаваемыми институциональными источниками, и неинституциональными (файенчекинг) оказывается подвижной: зачастую общество готово воспринимать утверждение, сделанное посредством социальных медиа, как новость в последней инстанции [Рябченко, Малышева 2019: 48]. В этой связи беспрепятственное распространение заведомо ложной и деструктивной информации под видом правдивых новостей способно формировать кризисы межличностного и институционального доверия, содействовать возникновению конфликтов и ставить под угрозу национальную безопасность государств и отдельных регионов [Ушкин 2019: 54].

В соответствии с данными опросов, проведенных ВЦИОМом (2000-2019 гг., 1600 респондентов), в 2019 г. $49 \%$ жителей России ответили, что почти всегда можно (7\%) или в большинстве случаев можно (42\%) отличить недостоверную информацию в СМИ и Интернете, а $42 \%$ ответили, что в большинстве случаев нельзя (29\%) или почти всегда нельзя (13\%). Почти половина россиян не могут отличить достоверную информацию от ложной. При этом $74 \%$ респондентов полагают, что недостоверная информация была опубликована умышленно, и $17 \%$ - что это явилось следствием непреднамеренной ошибки журналистов/ редакторов 1 .

Вместе с тем новость как событие сама по себе может не являться фейковой, но нести иные латентные угрозы деформации коммуникативных практик. Нам

\footnotetext{
1 Люди в цифре: эпоха «постправды». 2019. - Всероссийский иентр изучения общественного мнения. Доступ: https://wciom.ru/fileadmin/file/reports_conferences/2019/2019-12-13_ mediaforum.pdf (проверено 03.04.2021).
} 
показалось целесообразным изучить и проанализировать публикации СМИ с точки зрения наличия возможных рисков информационного потребления с использованием методики фрейм-анализа, предполагающего изучение в контексте социологии повседневности (повседневной жизни) процесса создания актов различения, именования, квалификации и последующего коммуникативного повествования. В качестве единицы анализа мы использовали статьи, темы и новости в прессе, размещенные в свободном доступе в Интернете и маркируемые темой «терроризм».

Признанным является тот факт, что отличительной особенностью терроризма является его динамичная коммуникативная сущность. Б. Хоффман отмечает, что «содержательное предназначение теракта - передать определенное послание» [Хоффман 2003: 191]. Использование террористическими организациями измененной глобальной информационно-коммуникативной взаимосвязи человечества, в т.ч. собственных медиапродуктов, сделало террористов деятельными участниками общемировой политики, в результате чего террористические организации получили возможность контролировать содержание сообщений, каналы распространения и механизмы получения ответной реакции целевой аудитории [Дементьева 2015: 31]. В совокупности возможностей эта особенность трактовки и непосредственного применения понятия способствует трансформации социальных отношений, в результате которой терроризм как социальное понятие приобретает системные качества, определяющие его наполнение и обозначение в современных социально-экономических и политических отношениях.

Несмотря на масштабирование информационного значения терроризма как неотъемлемого понятия социальной действительности мира угроз, его единая юридическая, понятийно-смысловая (социальная) дефиниция отсутствует. Термин приобрел, прежде всего, политическую окраску: в зависимости от политических интересов или целей политических противников определение «террористический» может маркировать организации или государства. В качестве примера отметим решение комитета по иностранным делам сената конгресса США, который одобрил законопроект, обязывающий главу Государственного департамента М. Помпео рассмотреть возможность признания России спонсором терроризма ${ }^{1}$. В январе 2020 г. парламент Ирана единогласно принял законопроект, согласно которому армия США после убийства иранского генерала К. Сулеймани в Ираке признается террористической организацией ${ }^{2}$. Эти примеры, на наш взгляд, являются иллюстрациями «наполнения по своему усмотрению» смыслового содержания понятия «терроризм».

Для целей нашего исследования выбор медиаисточников осуществлялся без учета их направленности, рейтинга, даты публикации и других факторов. Интересно само существование нового коммуникативного вызова - практического употребления понятия «терроризм». Однако «чтобы осмыслить предмет, с которым мы имеем дело, акторы должны начать с чего-то конкретного» [Яноу, ван Хульст 2011: 96]. Мы начали с процедуры кодирования значений, которое осуществлялось при помощи индикатора «соседи-террористы», поскольку нам показалось интересным провести исследование с позиций соответствия смысловых значений заголовков публикаций их семантическому

\footnotetext{
${ }^{1}$ Комитет Сената США одобрил законопроект о возможности признания РФ «спонсором терроризма». 2019. - Информационное агентство tass.ru. 15.10. Доступ: https://tass.ru/ mezhdunarodnaya-panorama/7326589 (проверено 02.02.2021).

2 Иранский парламент признал Пентагон террористической организацией. - Информационное агентство РИА-новости. 07.01.2020. Доступ: https://ria. $\mathrm{ru} / 20200107 / 1563159073 . \mathrm{html}$ (проверено 02.02.2021).
} 
содержанию. В лингвистике заголовок рассматривается как важнейший коннотативный элемент текста. К примеру, исследователь Л.И. Захарова выделяет две основные функции заголовка информационного сообщения: сигнальную функцию (заголовок должен привлекать внимание читателя) и информативную (заголовок должен давать представление о рассматриваемом тексте) [Захарова 2004: 104].

Мы предположили, что в рассматриваемых нами случаях различия между предоставляемой информацией и ее анонсом (заголовком), т.е. эксплуатация термина «терроризм» как слова-сигнала, может повлечь за собой последствия в виде нарушения коммуникативного процесса передачи - приема информации, «размывания» понимания этого определения, а также изменения внутренней среды соседских сообществ.

Поскольку после введения в поисковые строки транснациональных коммуникативных систем (браузеров) Яндекс и Гугл ключевых слов отобразилось более 2 млн результатов, размер выборки был ограничен путем отбора наиболее релевантных теме исследования публикаций за период с 2006 до 2020 г.

Активные ссылки поисковых строк содержали как официальные рекомендации о том, куда необходимо обращаться, если стало известно о планируемом совершении террористических актов, и какие действия необходимо предпринимать в случае террористической угрозы, так и публикации информационных агентств под заголовками: «Соседский террор: можно ли повлиять на соседа, донимающего жителей целого дома» (rus.delfi.ee) 1 , «Соседи-террористы» (tvernews) ${ }^{2}$, «Соседей террористов с Товарищеского проспекта напугала упавшая бетонная плита (topspb.tv) ${ }^{3}$, «Сосед-террорист: как бороться с необоснованными нападками» 4 (R.Tiger.com), «Бытовой «терроризм» по-смоленски (rabochy-put.ru $)^{5}$, «Соседи-террористы: война из-за парковки и собачьих фекалий» (rus.tvnet/lv) ${ }^{6}$, а также сайты сообществ, социальных сетей общественных организаций, содержащих экспертные мнения, и т.п. сообщения на заданную тему.

Результаты поискового запроса с критериями «как соседи терроризируют соседей», «бытовой терроризм» позволили «расширить» круг действий, которые, по мнению авторов статей, можно отнести к террористическим: «В Светлогорске мужчина терроризировал соседей и поджег свою квартиру»

1 Соседский террор: можно ли повлиять на соседа, донимающего жителей целого дома. - Новостной портал Delfi. 12.06.2006. Доступ: https://rus.delfi.ee/archive/sosedskijterror-mozhno-li-povliyat-na-soseda-donimayuschego-zhitelej-celogo-doma?id=12870763rg.ru (проверено 28.01.2021).

2 Реалити-шоу «Соседские войны» закончилось: Андрей Горев переехал и судится с соседом-«террористом». - Сетевое издание «Твое информационное агентство». 31.01.2018. Доступ: https://tvernews.ru/tags/sosedi-terroristy (проверено 28.01.2021).

3 Бытовая тревога: соседей террористов с Товарищеского проспекта напугала упавшая бетонная плита. - Телеканал Санкт-Петербург. 06.04.2017. Доступ: https://topspb.tv/ news/2017/04/6/bytovaya-trevoga-sosedej-terroristov-s-tovarisheskogo-prospekta-napugalaupavshaya-betonnaya-plita/ (проверено 28.01.2021).

4 Сосед-террорист: как бороться с необоснованными нападками. - R.Tiger. 05.10.2020. Доступ: https://rtiger.com/ru/journal/sosed-terrorist-kak-borotsya-s-neobosnovannyminapadkami/ (проверено 28.01.2021).

5 Бытовой «терроризм» по-смоленски. - Газета Рабочий путь. 15.03.2016. Доступ: https://www.rabochy-put.ru/society/72153-bytovoy-terrorizm-po-smolenski.html (проверено 28.01.2021).

6 Соседи-террористы: война из-за парковки и собачьих фекалий. - Новостной портал TVNET. 14.03.2016. Доступ: https://rus.tvnet.lv/5123598/sosedi-terroristy-voyna-iz-zaparkovki-i-sobachih-fekaliy (проверено 28.01.2021). 
$(k p . b y / o n l i n e){ }^{1}$, «Балашовец терроризирует соседей: “лишил” площадки и “распахал” асфальт для парковки» (Саратов 24) ${ }^{2}$, «Бомж Петрович терроризирует соседей вонью» («Комсомольская правда») ${ }^{3}$, «Жительница Словакии 16 лет терроризировала соседей “Травиатой” (новости mail.ru $)^{4}$, «Подъездный кувыркун из Твери продолжает терроризировать соседей» $(\text { tver. } k p . r u)^{5}$, «Плюшкин из Вешняков терроризирует соседей ордами тараканов и мух» $(360 t v . r u)^{6}$, «Новые арендаторы лофта Дмитрия Лошагина терроризируют соседей шумными вечеринками» (newdaynews.ru) 7 .

Массовость таких заголовков свидетельствует, на наш взгляд, о формирующейся коммуникативной практике привлечения внимания к публикациям посредством произвольного или квазиформализованного написания «словсигналов», а также подбора соответствующих мест и времени распространения информации, ротации сообщений и т.п.

Действия и поведение «героев» подобных публикаций нарушают привычный образ жизни окружающих людей, деформируют их жизненное пространство, процессы общения и взаимодействия в социуме. В некоторых ситуациях навязчивые действия служат ответной реакцией (развернутой обратной коммуникацией). Так, «пытка музыкой» при последующем рассмотрении проблемы началась из-за неумолчного лая соседской собаки, беспокоившего жительницу Словакии. Публикация на тему «Сосед-террорист: как бороться с необоснованными нападками» содержит рекомендации, как противостоять соседям, устанавливающим «излишне строгие» правила проживания в доме.

Таким образом, анализ содержательного наполнения текстовых массивов и продуктов коммуникативной корреспонденции и соотношение их с заголовками позволили сделать вывод, что значительному числу пользователей под ярлыком «террористической» предоставляется информация о действиях, которые не могут являться таковыми ни при каких обстоятельствах - асоциальное или хулиганское поведение, в т.ч. уничтожение имущества, нарушение санитарных норм и т. п.

Исследование нами было продолжено на ресурсе открытой электронной платформы Change.org. После введения в поисковой строке маркера «террористы» нами были найдены петиции: «Мы требуем еврейского большинства во всех общественных и политических организациях!!!, из текста которой следовало, что во властных структурах Израиля находятся террористы и мафия в связи с

1 В Светлогорске мужчина терроризировал соседей и поджег квартиру. - Комсомольская правда. 05.11.2015. Доступ: https://www.kp.by/online/news/2212076/ (проверено 02.02.2021).

2 Балашовец терроризирует соседей: «лишил» плошадки и «распахал» асфальт для парковки. - Новостной портал Саратов 24. 05.08.2018. Доступ: https://saratov24.tv/ news/balashovets-terroriziruet-sosedey-lishil-ploshchadki-i-raspakhal-asfalt-dlya-parkovki/ (проверено 02.02.2021).

3 Бомж Петрович терроризирует соседей вонью. - Комсомольская правда. 03.06.2010. Доступ: https://www.chel.kp.ru/daily/24501.4/653237/ (проверено 02.02.2021).

4 Жительница Словакии 16 лет терроризировала соседей «Травиатой». - Новостной nортал Mail.ru. 07.08.2018. Доступ: https://news.mail.ru/society/34341024/ (проверено 03.02.2021).

5 Подъездный кувыркун из Твери продолжает терроризировать соседей. - Комсомольская правда. 28.05.2017. Доступ: https://www.tver.kp.ru/online/news/2758903/ (проверено 03.02.2021).

6 Плюшкин из Вешняков терроризирует соседей ордами тараканов и мух. - Новостной nортал 360tv.ru. 04.06.2018. Доступ: https://360tv.ru/news/obschestvo/zhitel-veshnjakovterroriziruet-sosedej-ordami-tarakanov-i-muh/ (проверено 04.02.2021).

7 Новые арендаторы лофта Дмитрия Лошагина терроризируют соседей шумными вечеринками. - Российское информационное агентство «Новый день». 26.01.2016. Доступ https://newdaynews.ru/ekb/555689.html (проверено 04.02.2021). 
пренебрежением правом еврейского государства на существование и правом еврейского народа на самоопределение ${ }^{1}$; «Запретить деятельность коммунистических партий в России», поскольку их идейно-теоретический базис и руководство к действиям основано на террористической идеологии ${ }^{2}$; «Поддержим план Сергея Глазьева по выходу из МВФ!», согласно которой Международный валютный фонд как основная причина коррупции в стране, экономического беспредела и социальной несправедливости является террористическим 3 ; «Twitter, Facebook и Google должны заблокировать Гуайдо, Навального, Вонга и им подобных», в соответствии с которой в связи с блокировкой американскими соцсетями аккаунтов Д. Трампа и его советников, названных «внутренними террористами», предлагается заблокировать аккаунты Х. Гуайдо, А. Навального, О. Ляшко ${ }^{4}$ « «Ппасите “Пальмиру” Смоленщины!», в которой последствия бездействия уполномоченных органов по реставрации храма сошествия Святого Духа в Талашкино сравнивается с уничтожением террористами древних памятников Пальмиры 5 ; «Привлечь пропагандиста Дмитрия Киселева за оправдание и пропаганду терроризма» за высказывания в эфире телепрограммы «Вести недели с Дмитрием Киселевым» 6.

Интересной нам также показалась информация журналистки из Грозного М. Мазаевой, которая в Твиттере разместила пост, что перевод с русского языка на английский язык посредством платформы Яндекс.Переводчик (traslate. yandex.ru), для обеспечения деятельности которого используется гибридная модель машинного перевода, включающая в себя нейросетевой (анализирует массив параллельных текстов, учится находить в них закономерности и составляет списки всех употребляемых слов и фраз) и статистический (основан на моделях языка и перевода) подходы ${ }^{7}$, слова «чеченский» с русского на английский язык сопровождается примером: «Да он же бывший чеченский террорист». При этом в службе техподдержки Яндекса ответили, что это были не редакторские, а «автоматические примеры» 8 .

Во время информационного освещения терактов СМИ превращаются в «ретранслятор» актов устрашения/разрушения между террористами и адреса-

1 Мы требуем еврейского большинства во всех общественных и политических организациях!!! Доступ: https://www.change.org/p/правительству-израиля-депутатамвсех-сионистских-партий-кнессета-и-верховным-судьям-мы-требуем-еврейскогобольшинства-во-всех-общественных-и-политических-организациях (проверено 05.04.2021).

2 Запретить деятельность коммунистических партий в России. Доступ: https://www. change.org/p/генеральная-прокуратура-российской-федерации-запретить-деятельностькоммунистических-партий-в-россии (проверено 05.04.2021).

3 Поддержим план Сергея Глазьева по выходу из МВФ! Доступ: https://www.change. org/p/народу-российской-федерации-поддержим-план-сергея-глазьева-по-выходу-измвф (проверено 05.04.2021).

4 Twitter, Facebook и Google должны заблокировать Гуайдо, Навального, Вонга и им подобных. Доступ: https://www.change.org/p/joseph-biden-twitter-facebook-и-googleдолжны-заблокировать-гуайдо-навального-вонга-и-им-подобных (проверено 05.04.2021).

5 Спасите Пальмиру Смоленщины. Доступ: https://www.change.org/p/министрукультуры-рф-спасите-пальмиру-смоленщины (проверено 05.04.2021).

6 Привлечь пропагандиста Дмитрия Киселева за оправдание и пропаганду терроризма. Доступ: https://www.change.org/p/директору-фсб-рф-бортникову-а-в-привлечьпропагандиста-дмитрия-киселева-за-оправдание-и-пропаганду-терроризма (проверено $05.04 .2021)$.

7 О машинном переводе. Руководство разработчика. Доступ: https://yandex.ru/dev/ translate/doc/dg/concepts/how-works-machine-translation.html (проверено 05.04.2021).

8 Milana Mazaeva в Твиттере. Доступ: https://twitter.com/GroznyMazay/status/ 1335167089385082881 (проверено 05.04.2021). 
тами террористической деятельности - обществом и властью. Широкое освещение в СМИ подробностей, имен и деталей инцидентов порождает последствия в виде эффекта подражающих инцидентов и заражения деструктивными идеями [Карпова, Максимова 2021: 106].

Мы выяснили, что в повседневной деятельности СМИ и мобильные сетевые пользователи произвольно обозначают термином «терроризм» действия, не являющиеся таковыми по своей сути. Основаниями «яркого маркирования» публикаций служит интерес быстрой информационной манифестации сообщений, желание привлечь внимание к сложным проблемам общества в организации повседневного мира человека либо эксплуатация посредством трансляции «образа терроризма» для достижения личных целей. Это, на наш взгляд, может повлечь за собой непреднамеренные последствия возникновения «встречных» социальных рисков и угроз коммуникативного противодействия взаимодействующих сторон в связи с постоянным «нахождением терроризма» в общественном дискурсе, в т.ч. в условиях «несовершения» террористических актов.

Можно предположить, что в XXI в. терроризм становится социально-политическим маркером активного присутствия в повседневных коммуникативных практиках, подтверждая подлинность участников и их действий в медийном пространстве и виртуальных сообществах. Французский социолог Ж. Бодрийяр отмечал, что «терроризм, как и вирусы, повсюду. Больше нет демаркационной линии, которая позволяла бы его обозначить, терроризм находится в самом сердце культуры, которая с ним борется» [Бодрийяр 2017: 101].

В XX-XXI вв. искажение (distortion) коммуникативного процесса передачи - получения информации становится характерным свойством средств коммуникации. Производство аберраций информации во всех звеньях коммуникативной цепи ведет к рассогласованности (декогеренции) процесса, т.е. к становлению информационной аномии [Карпова 2017: 115].

Проведенное нами исследование демонстрирует опосредованное привнесение СМИ элементов неопределенности в понимание обществом понятия «терроризм», что частично способствует его ассимиляции в повседневные практики бытового употребления. В результате терроризм не присутствует «где-то за границами обыденной жизни современного жителя», а непосредственно включается в общий повседневный мир каждого, что может спровоцировать абсолютно любые сложные ощущения при его частном обозначении и интерпретации.

Повседневный мир представляет собой смысловой континуум, который интерпретируется людьми посредством типизации и структурирования объектов этого мира [Жигунова 2015: 67]. Повседневные практики участников коммуникации формируют (и деформируют) своим взаимодействием понятия и значения, являющиеся на протяжении длительного времени скрепами общественной жизни. Наряду с явными угрозами и ограничителями традиционных приемов взаимодействия, эти коммуникации характеризуют уровень быстрых, «реактивных» отношений, складывающихся в современном мире между участниками повседневных взаимодействий.

\section{Список литературы}

Бодрийяр Ж. 2017. Дух терроризма. Войны в заливе не было (пер. с фр. А. Качалова). М.: РИПОЛ классик. 226 с.

Вахштайн В.С. 2007. Теория фреймов как инструмент соииологического анализа повседневного мира: автореф. дис... к.соц.н. М.: ГУ ВШЭ. 25 с.

Дементьева К.В. 2015. Проблема терроризма и особенности ее освещения в СМИ. - Журналистский ежегодник. Томск: УПТ ТГУ. № 4. С. 30-33.

Жигунова Г.В. 2015. Повседневность как социальный феномен. - Современные 
исследования социальных проблем: электронный научный журнал. № 8(52). C. 56-71.

Захарова Л.И. 2004. Феномен языковой игры в современной публицистике. - Проблемы фразеологической и лексической семантики: материалы международной научной конференции. М.: ИТИ «Технологии». С. 104-107.

Карпова А.Ю. 2017. Маркеры и эффекты информационной аномии в политической коммуникации. - Вестник Томского государственного университета. Философия. Социология. Политология. № 40. С. 112-121.

Карпова А.Ю., Максимова Н.Г. 2021. Скулшутинг в России: что имеет значение? - Власть. Т. 29. № 1. С. 93-108.

Комаров Е.Н. 2014. Язык СМИ: к вопросу о роли СМИ в формировании медиакартины мира. - Lingua Mobilis. № 3(49). С. 122-129.

Рябченко Н.А., Малышева О.П. 2019. Трансформация социально-политической коммуникации: структурно-реляционный анализ феномена fake-news. Социальная инженерия: как социология меняет мир: материалы IX Международной социологической Грушинской конференции. М.: Изд-во ВЦИОМ. С. 46-52.

Ушкин С.Г. 2019. Fake news и проблема доверия. - Социальная инженерия: как социология меняет мир: материалы IX Международной социологической Грушинской конференции. М.: Изд-во ВЦИОМ. С. 53-57.

Харламова Ю. 2012. СМИ как инструмент реализации государственной политики. - Власть. № 8. С. 41-45.

Хоффман Б. 2003. Терроризм - взгляд изнутри. М.: У-Фактория. 264 с.

Шюц А. 2004. Избранное: Мир, светящийся смыслом. М.: РОССПЭН. 1054 с.

Яноу Д., ван Хульст М. 2011. Фреймы политического: от фрейм-анализа к анализу фреймирования. - Социологическое обозрение. Т. 10. № 1-2. С. 87-113.

BELIK Elena Aleksandrovna, postgraduate student of the Chair of Social Sciences, Social and Psychological Institute, Kemerovo State University (6 Krasnaya St, Kemerovo, Russia, 650000; eabelik@mail.ru)

GOLOVATSKY Evgeniy Vasil'evich, Cand.Sci. (Soc.), Associate Professor; Associate Professor of the Chair of Social Sciences, Social and Psychological Institute, Kemerovo State University (6 Krasnaya St, Kemerovo, Russia, 650000; xomaik@rambler.ru)

\section{TRANSFORMATION OF THE CONCEPT OF TERRORISM IN THE SOCIO-POLITICAL PRACTICES OF MODERN RUSSIAN EVERYDAY LIFE}

\footnotetext{
Abstract. The meaning of the concepts used in the field of socio-political relations has recently undergone a significant transformation, both in its main meaning and in terms of the resonance of civic perception. This is due to a change in the volume, quality and rules of information transfer in the $20^{\text {th }}$ and $21^{s}$ t centuries. At the same time, risks and threats arising in the process of production-transfer of the quality of indicating information about something may be hidden and lead to unintended consequences, including distortion of the recognition/definition of meanings. Such risks can be provided both by the social phenomenon of the post-truth era - fake news, and by a violation, including unconscious one, of the procedure for creating acts of distinction, naming, qualification for the purpose of subsequent communicative narrative. The authors propose results of the analysis of media publications related to the practice of daily reporting on one of the global threats to the post-modern world (terrorism). They found out that the semantic meaning of the titles of the publications, such as terrorist neighbors, neighbor terror, definitely differ in the content of the internal meaning. The obtained data of the free designation of the concept make it possible to conclude that terrorism was included in the everyday practices of people, which carries the risks of distorting the system of social codes and values.
}

Keywords: everyday interaction, sociological research, terrorism, interpretations, socio-political interaction 